\title{
A Rare Case of Holoprosencephalus with Cyclopia
}

\author{
Aliou Diouf $1,2,3^{*}$, Ousmane Thiam ${ }^{1,3}$, Cheikh C. T. Sarr', Djibril B. Sow ${ }^{1}$, Mamour Gueye ${ }^{2}$, \\ Mame D. Ndiaye' ${ }^{2}$, Magatte Mbaye $^{3}$ \\ ${ }^{1}$ Regional Hospital Center of Saint-Louis, Saint-Louis, Senegal \\ ${ }^{2}$ Gynecological and Obstetric Clinic, EPS Aristide Le Dantec, Dakar, Senegal \\ ${ }^{3}$ Gaston Berger University, Saint-Louis, Senegal \\ Email: *alioudiouf69@yahoo.com
}

How to cite this paper: Diouf, A., Thiam, O., Sarr, C.C.T., Sow, D.B., Gueye, M., Ndiaye, M.D. and Mbaye, M. (2020) A Rare Case of Holoprosencephalus with Cyclopia. Open Journal of Obstetrics and Gynecolo$g y, 10,976-980$

https://doi.org/10.4236/ojog.2020.1080092

Received: June 17, 2020

Accepted: July 31, 2020

Published: August 3, 2020

Copyright $\odot 2020$ by author(s) and Scientific Research Publishing Inc. This work is licensed under the Creative Commons Attribution International License (CC BY 4.0).

http://creativecommons.org/licenses/by/4.0/

\begin{abstract}
Cyclopia is a rare genetic defect. It is the most severe form of alobar holoprosencephaly, characterized by the fusion of the two orbits and is linked to the lack of development of the frontal bud falling within the framework of ectroprosopia. Case presentation: This is a case report of Gravida 3 Para 3, 32 years old and without a history of abortion, with a history of normal vaginal birth which occurs during labor latency with active movements of the fetus present and cardiac activity on auscultation with pinard stethoscope. The uterine height was $32 \mathrm{~cm}$ with well palpated fetal poles. Ultrasound examination confirms the presence of normal cardiac activity with a poorly responsive fetus. After labor management, she gave birth 3 hours after admission to the maternity ward of a living newborn male weighing $2800 \mathrm{~g}$ with an Apgar score of $4 / 10$ at the first minute and $2 / 10$ at the fifth minute. He died 10 minutes later at the maternity hospital of the Saint-Louis regional hospital center, in northern Senegal. Conclusion: Holoprosencephaly is certainly rare but remains the most common structural congenital anomaly of the brain with a complex and multifactorial pathogenesis. Early perinatal diagnosis and determination of severity are important to inform parents of the possibilities of a future life. The voluntary termination of pregnancy is an option but remains prohibited in the country to this day for these indications.
\end{abstract}

\section{Keywords}

Holoprosencephalus, Fetus, Cyclopia, Saint-Louis

\section{Introduction}

Cyclopia is a rare genetic defect with a frequency of $0.06 \%$ [1] [2]. It is the most 
severe form of alobar holoprosencephaly, characterized by the fusion of the two orbits and is linked to the lack of development of the frontal bud falling within the framework of ectroprosopia [3].

Holoprosencephaly is a developmental defect of the embryonic forebrain, or prosencephalon that is commonly associated with midfacial defects. The defect results from incomplete development of central nervous system structure and has different spectrums including, alobar, semilobar and lobar. Severe forms of holoprosencephaly are associated with severe facial midline defects, such as a primitive nasal structure (proboscis) [4] [5].

The incidence in live birth is estimated 1/16,000 [1]. Pathogenesis of holoprosencephaly is complex involving teratogenic exposures like Ethanol, genetic abnormalities and syndromic associations [6]. Maternal Diabetic is a well-established associated risk factor with 200-fold increase the incidence [1] [2].

This is a clinical case of holoprosencephalus with cyclopia reported for the first time in our hospital since its existence dating back to 1822 .

\section{Case Presentation}

This is a case report of Gravida 3 Para 3, 32 years old and without any history of abortion or another anomaly before. The patient was received at the first part of the labor with active movements of the fetus and cardiac activity. The fetal heart tones are in 140, not very reactive but without decelerations and the uterine height was $32 \mathrm{~cm}$ with well palpated fetal poles.

Ultrasound examination confirms the presence of normal cardiac activity with a poorly responsive fetus.

After labor management, she gave birth 3 hours after admission to the maternity ward of a living newborn male weighing $2800 \mathrm{~g}$ with an Apgar score of 4/10 at the first minute and 2/10 at the fifth minute. He died 10 minutes later at the Saint-Louis regional hospital center maternity, in northern Senegal.

During her pregnancy, the woman had a correct prenatal follow-up with 5 good quality consultations and a prenatal assessment made in the first trimester of pregnancy.

She did two obstetrical ultrasounds without any anomaly detected. The blood sugar returned to normal as well as the toxoplasmosis, rubella and syphilis serologies. Her hemoglobin was $11 \mathrm{~g} / \mathrm{dL}$.

The Examination of the newborn at birth revealed a single eye located on the midline, with no nasal opening or tube. Both ears were present and anatomically normal and there was no cleft palate (Figure 1).

The umbilical cord and the spine showed no particularities, as did the other organs. The post mortem examination was not performed because the service was not available in the hospital.

There were no abnormalities for the mother in the postpartum period.

\section{Discussion}

This case report that we have presented is a unique case of severe form of 

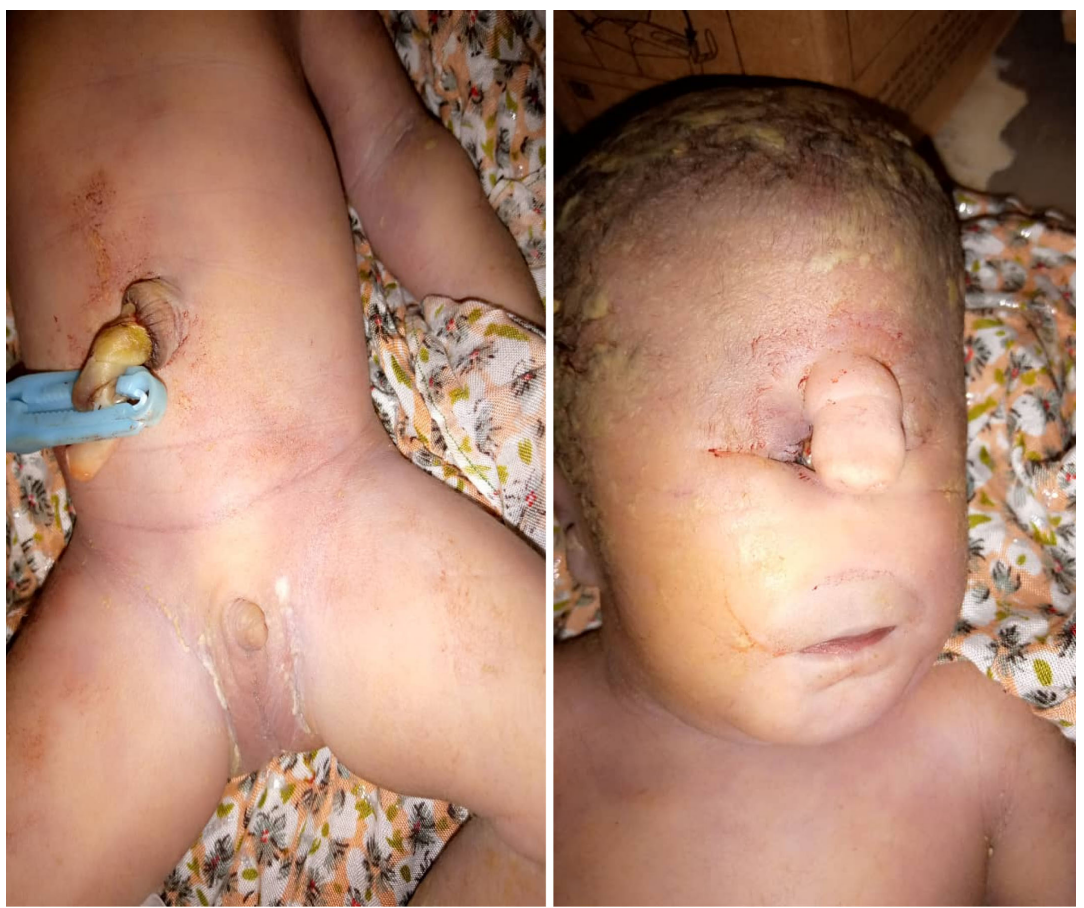

Figure 1. Fetus with a single eye located on the midline, with no nasal opening.

holoprosencephaly with cyclopia diagnosed in the postnatal period at the regional hospital center of Saint-Louis, in the north of Senegal in Africa. The exact cause of holoprosencephaly is not known, but research has revealed that there are multiple risk factors, including teratogenic exposures and genetic causes. We can cite the long use of aspirin, statins, poor glycemic control (hyperglycemia), methotrexate and excessive alcohol consumption [7] [8]. However, in the case presented, the patient was not exposed to any of its factors. Likewise, our patient did not show any bleeding during pregnancy and her obstetric history shows no particularities. However, no significant correlation has been reported between the incidence of holoproencephaly and maternal age [1] [8].

TORCH infections in early pregnancy can potentially affect neurological embryogenesis leading to holoprosencephaly but in our case these were excluded [2].

An autosomal dominant heritage certainly exists, but in rare cases of holoprosencephaly. Trisomy 13 and 18 can be associated with cyclopia or possibly associated with other chromosomal abnormalities or occasionally with normal chromosomes

It commonly occurs at the beginning of gestational life causing a lack of cleavage from the hemisphere to the right and left cerebral hemisphere [2] [5].

The neural tube forms three primary vesicles, the forebrain, the midbrain and the rhombencephalon from the first gestational life. The prosencephalon was then divided into telencephalon and diencephalon in the 5th gestational age. The failure of the complete or partial division of the development of the prosencephalon in the hemispheres and lobes leads to this holoprosencephaly, a 
complex neural anomaly [9] [10] [11].

Holoprosencephaly is diagnosed before birth but requires a high index of suspicion. However, in our case, the diagnosis was not made despite the prenatal ultrasound examination, the main clinical manifestations of EHP are the absence of the eyes, ceocephaly, cyclopia and proboscis.

The first diagnoses of alobar, semi-lobar and lobar HPA are reported during weeks $9.5,13$ and 21 of pregnancy, respectively [6].

\section{Conclusion}

Holoprosencephaly is certainly rare but remains the most common structural congenital anomaly of the brain with a complex and multifactorial pathogenesis. Early perinatal diagnosis and determination of severity are important to inform parents of their baby's life chances. The voluntary termination of pregnancy is an option but remains prohibited in our country for these kinds of indications.

\section{Conflicts of Interest}

The authors declare no conflicts of interest regarding the publication of this paper.

\section{References}

[1] Chukuemaka, A. and Cecil, A. (2009) Holoprosencephaly in a Nigerian Female: A Case Report. Nigerian Health Journal, 9, 30-33.

[2] Mehrbanu, A., Akram, S., Ashraf, S., Kerami, A., Abdollahimohammad, A., Mirshekari, F., et al. (2015) Alobar Holoprosencephaly: A Case Report. Journal of Nursing and Midwifery Sciences, 4, 70-74. https://doi.org/10.18869/acadpub.jnms.2.4.70

[3] SrinivasaBabu, C.R., Vineel, I., Prakash, A. and Kumar, Y.R. (2017) Antenatally Diagnosed Alobarholoprosencephaly: A Report of Two Cases. CHRISMED Journal of Health and Research, 4, 283-285. https://doi.org/10.4103/cjhr.cjhr_23_17

[4] Rathod, S., Samal, S.K. and Begum, J. (2015) Holoprosencephaly with Cyclopia: A Rare Case Report. International Journal of Otorhinolaryngology and Head and Neck Surgery, 1, 37-39. https://doi.org/10.18203/issn.2454-5929.ijohns20150586

[5] Patil, V., Taori, K., Sardesai, N. and Ingle, V. (2005) Semi Lobar Holoprosencephaly-A Case Report. Indian Journal of Radiology \& Imaging, 15, 576. https://doi.org/10.4103/0971-3026.29177

[6] Otuaga, P., Eweka, A., Oni, A. and Ebite, L. (2007) Cyclops Deformity in Benin City, Nigeria: A Case Report. Internet Journal of Neurology, 10, 1-4.

[7] Hong, M. and Krauss, R.S. (2017) Ethanol Itself is a Holoprosencephaly-Inducing Teratogen. PLoS ONE, 12, e0176440. https://doi.org/10.1371/journal.pone.0176440

[8] Poenaru, M.O., Ionut, D. and Marin, A. (2012) Holoprosencephaly: Two Case Report. Maedica (Buchar), 7, 58-62.

[9] Folkerth, R.D. and Lidov, H.C.G. (2012) Congenital Malformations, Perinatal Diseases, and Pharcomatoses. 2nd Edition, Elsevier, Philadelphia, USA, 96-182.

[10] Cohen Jr., M.M. (2006) Holoprosencephaly: Clinical, Anatomic, and Molecular Dimensions. Birth Defects Research Part A: Clinical and Molecular Teratology, 76 
A. Diouf et al.

658-673. https://doi.org/10.1002/bdra.20295

[11] Gebre, S., Tsehaye, E. and Abate, E. (2019) Holoprosencephalus with Cyclopia: A Case Report. Annals of Clinical Case Reports, 4, 1740. 